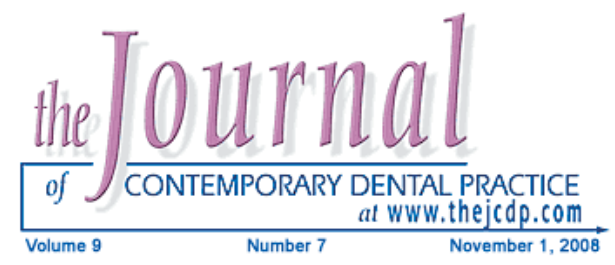

\title{
Comparative Evaluation of Subgingivally Delivered 10\% Doxycycline Hyclate and Xanthan-based Chlorhexidine Gels in the Treatment of Chronic Periodontitis
}

\section{Rajan Gupta, MDS; Nymphea Pandit, MDS;}

Shweta Aggarwal, MDS; Ashish Verma, MDS
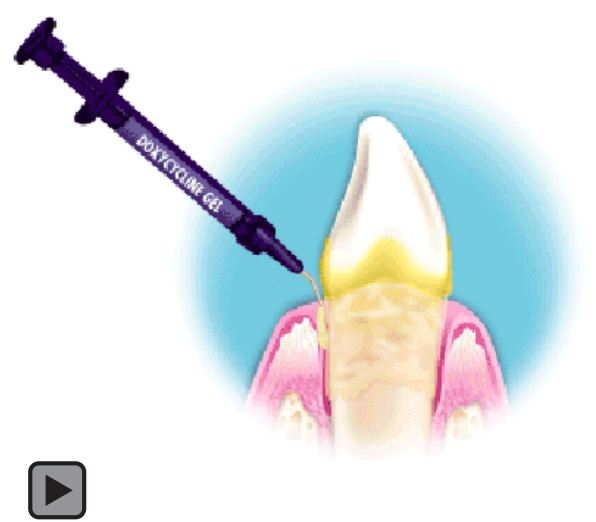

\begin{abstract}
Aim: The aim of this study was to evaluate and compare the efficacy of subgingivally delivered $10 \%$ doxycycline hyclate and xanthan based chlorhexidine gels when used as an adjunct to scaling and root planing (SRP) in the treatment of chronic periodontitis.

Methods and Materials: A randomized, controlled, single center study was conducted involving 90 sites in 30 patients suffering from moderate to advanced chronic periodontitis. Each patient contributed three sites which were randomized to three treatment groups: SRP + insertion of doxycycline gel [SRP+DH], SRP + insertion of chlorhexidine gel [SRP+CHX]), and SRP alone [SRP]. Gingival index (GI), plaque index (PI), probing pocket depth (PPD), and clinical attachment level (CAL) were recorded at baseline, 1 month, and 3 months post therapy.

Results: All treatments showed significant reductions in PPD and CAL at 1 and 3 months when compared to baseline values $(p<0.001)$. At 3 months, sites treated with $S R P+D H$ and $S R P+C H X$ showed an additional reduction in PPD of $0.86 \pm 1.0 \mathrm{~mm}$ and $0.66 \pm 1.58 \mathrm{~mm}$, respectively, significantly greater than SRP alone $(p<0.02)$. Differences in mean PPD reduction between SRP+DH and SRP+CHX were not significant $(p=0.46)$.
\end{abstract}

○) Seer Publishing 
At 3 months, differences in relative CAL between both SRP+DH $(0.80 \pm 0.92)$ and $\mathrm{SRP}+\mathrm{CHX}(0.63 \pm 1.47)$ and $\mathrm{SRP}$ alone were statistically significant $(\mathrm{p}<0.02)$. Differences in relative $C A L$ between $\mathrm{SRP}+\mathrm{DH}$ and $\mathrm{SRP}+\mathrm{CHX}$ were not significant $(p=0.54)$.

Conclusion: The results suggest treatment with 10\% doxycycline hyclate and xanthan based chlorhexidine gels as an adjunct to SRP improves PPD and CAL patients with periodontitis compared to SRP alone.

Clinical Significance: The use of local drug therapy may refocus the need for surgical periodontal therapy toward deeper pockets.

Keywords: Randomized clinical trial, local drug delivery, doxycycline gel, chlorhexidine gel, scaling and root planning, SRP

Citation: Gupta R, Pandit N, Aggarwal S, Verma A. Comparative Evaluation of Subgingivally Delivered 10\% Doxycycline Hyclate and Xanthan-based Chlorhexidine Gels in the Treatment of Chronic Periodontitis. J Contemp Dent Pract 2008 November; (9)7:025-032.

\section{Introduction}

The goals of periodontal therapy have evolved to parallel our understanding and interpretation of the causes of periodontal diseases. During the

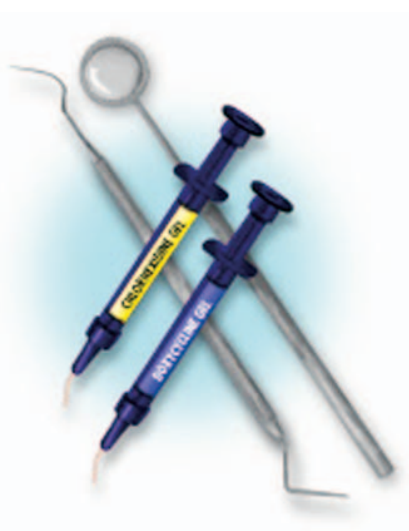
non-specific plaque era (1965-1975), therapeutic goals were directed at total elimination of microbial deposits in the gingival area. During the bacterial specificity era (1975-1985), therapy was directed towards suppression and elimination of putative periodontal

pathogens. Now, during the host bacterial interaction era, the emphasis remains on elimination or control of microbial organisms but attention is also directed toward how the host responds to these organisms. With the increasing awareness of the bacterial etiology of periodontal diseases a more direct approach using antibacterial agents has become an integral part of the therapeutic armamentarium. ${ }^{1}$

Many different delivery systems containing various antimicrobial agents have been developed as non-mechanical therapies for periodontitis targeting these agents directly to the bacterial pathogens within the periodontal pockets. The classic methods of drug delivery for treatment of periodontal diseases have several limitations. Systemic delivery can achieve only relatively low drug levels and exposes the rest of the body to potential side effects. ${ }^{2}$ Local application of solutions, either by mouthwash or by irrigation, depends on first order kinetics which requires high initial concentrations and multiple applications in order to provide sustained effectiveness. Both suffer from poor control of patient compliance. ${ }^{2}$ If an antimicrobial agent is irrigated subgingivally, it is rapidly cleared out by the flow of gingival fluid. Oosterwaal and coworkers (1990) demonstrated the half-life of a fluorescien gel deposited into a periodontal pocket was 12.5 minutes. ${ }^{3,4}$

In contrast, local drug delivery can provide high drug concentration, minimal side effects, less reliance on patient compliance for taking the medication, and avoids treating the patient systemically. ${ }^{5}$ Controlled delivery systems produce concentration profiles which are more constant and last longer than the other delivery systems. The basic components of controlled delivery devices may be divided into three basic elements: the drug reservoir, the rate controlling element, and the biological platform. The biological platform represents the controlled delivery and is equivalent to substantivity. ${ }^{2}$

Tetracycline antibiotics, including doxycycline, have been introduced as adjuncts in the treatment 
of periodontal disease. Tetracyclines gain access to bacterial cells by the combined processes of passive diffusion through outer-membrane pores and active transfer utilizing an energy dependent pump in the inner membrane. The drug then acts by inhibiting protein synthesis on the surfaces of the $30 \mathrm{~S}$ ribosomes. The rationale for the introduction of doxycycline as an adjunct to periodontal therapy was its broad spectrum bacteriostatic activity that could shift the potentially harmful gram-negative subgingival flora into gram positive flora which is more compatible with periodontal health. ${ }^{5,6}$ The properties of doxycycline which seem to be useful in periodontal therapy, in addition to its anti-bacterial pharmacological properties, include: antiproteolytic and anticollagenase activity; anti-inflammatory properties to suppress PMN activity; inhibition of bone resorption; and the scavenging action on reactive oxygen metabolites ${ }^{7,8}$ Demirel et al. ${ }^{9}$ showed doxycycline to be substantive to both cementum and dentin, suggesting root surfaces could serve as substrates for the deposition and subsequent slow release of doxycycline.

Chlorhexidine is a highly effective antimicrobial agent extensively studied and shown to be effective as a mouthrinse in concentrations of $0.12 \%$ to $0.2 \%$ against supragingival plaque bacteria. It has been shown to bind to the tissues from where it is released over 6-12 hours, prolonging the bactericidal effect. Recently, a new local drug delivery system, xanthan based chlorhexidine gel, has been developed. The chlorhexidine confers the characteristic of active and passive sterility to the formulation, which prevents re-colonization of pathogenic microorganisms in the application site, and also increases the mucoadhesion of the xanthan gel, occluding the application site. Chlorhexidine is present at a concentration of $1.5 \%$, of which $0.5 \%$ is in the form of fast releasing digluconate and $1.0 \%$ is in the form of slow releasing dihydrochloride. ${ }^{10}$

Many clinical studies have been conducted to assess the efficacy of local drug delivery systems as adjuncts to scaling and root planing (SRP) or as the sole treatment for untreated periodontal lesions. Few studies have assessed the comparative efficacy of a number of currently marketed systems.
The aim of the present study was to evaluate and compare the efficacy of two marketed local drug delivery gel products, Atridox ${ }^{\mathrm{TM}}$ a $10 \%$ doxycycline hyclate gel (Block Drug Corporation, Inc., Jersey City, NJ, USA) (currently marketed in the US by TOLMAR, Inc. Fort Collins, CO, USA) and Chlosite ${ }^{\circledR}$ a xanthan based chlorhexidine gel (GHIMAS, Italy) used as an adjunct to SRP in the treatment of chronic periodontitis.

\section{Methods and Materials}

This clinical trial was designed as a prospective, single center, randomized, controlled, split mouth study of 3 months duration.

\section{Patient Sample}

A total of 30 adult patients with moderately advanced chronic periodontitis were recruited from the outpatient Department of Periodontics, D.A.V. (C) Dental College and Hospital, Yamunanagar (Haryana). Approval of the study was obtained from the Institutional review board of Kurukshetra University, Haryana, India to which D.A.V. (C) Dental College and Hospital, Yamunanagar is an affiliated institution.

\section{Inclusion Criteria}

Male and female subjects between the ages of 25-75 years were included in this study if they had:

- Untreated moderate to severe periodontitis or recurrent periodontitis without periodontal surgery at least for the last 24 months

- A minimum of three teeth, distributed in the mouth to represent isolated experimental units (i.e., at least one tooth apart), with probing pocket depth (PPD) of $5 \mathrm{~mm}$ to $8 \mathrm{~mm}$ that bled on probing at the initial visit. ${ }^{11}$

- Voluntarily signed an informed consent agreement

- Completed a satisfactory health history questionnaire

Exclusion Criteria

Subjects were excluded if they:

- Had a history of oral candidiasis

- Had allergies to doxycycline hyclate or other tetracyclines or to chlorhexidine

- Were pregnant and lactating, if female

- Had any teeth with a periodontal pocket extending to the apex because of possible 
endodontic/periodontal complications

- Had received subgingival instrumentation (SRP) less than 2 months prior to the baseline examination $^{11}$

\section{Treatments}

Three sites were selected in each subject and were randomly assigned to one of the three treatments according to split mouth design. The teeth were in different quadrants, but in cases where there were two teeth in the same quadrant requiring treatment the gel was placed one tooth apart.

- $10 \%$ Doxycycline hyclate gel + SRP (DH+SRP)

- Xanthan based chlorhexidine gel + SRP (CHX+SRP)

- SRP alone as a control

\section{Clinical Examination}

Subjects were evaluated at baseline, 1 month, and 3 months. Clinical examinations included the following variables:

- Plaque index $(\mathrm{PI})^{12}$

- Gingival index $(\mathrm{Gl})^{13}$

- Probing pocket depth (PPD): the distance between gingival margin and the bottom of the probeable pocket assessed by the use of a UNC no. 15 manual probe and recorded to the nearest whole $\mathrm{mm}$.

- Clinical attachment level (CAL): the distance from cemento-enamel junction (CEJ) to the base of the pocket.

- Gingival margin location (GM): the distance from the CEJ, or another well defined landmark (acrylic stent) on the tooth, to the gingival margin measured with periodontal probe.

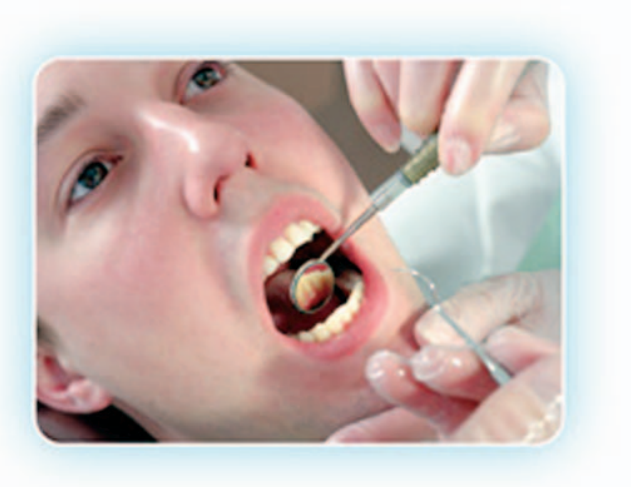

CAL is calculated using the formula CAL = PPD GM. A reference splint gave the location of probing by notches and served as reference for the vertical relative attachment levels. ${ }^{14}$

The measurements were carried out at four sites around each tooth (mesio-buccal, mid-buccal, disto-buccal, and mid palatal/lingual). At baseline, alginate impressions were taken and occlusal acrylic stents were fabricated for the measurement of attachment levels. In addition, at each visit subjects were interviewed concerning occurrence of any adverse events and use of concomitant medications and treatment.

\section{Drug Delivery Systems}

Atridox ${ }^{\mathrm{TM}}$ (Block Drug Corporation, Inc., Jersey City, NJ, USA) (currently marketed in the US by TOLMAR, Inc. Fort Collins, CO, USA) consists of doxycycline hyclate $(\mathrm{DH})$ and is a subgingivally controlled-release product composed of a two syringe mixing system. Syringe A contains $450 \mathrm{mg}$ of the ATRIGEL delivery system, which is a bioabsorbable (27 days), ${ }^{4,5}$ flowable polymeric formulation composed of $36.7 \% \mathrm{w} / \mathrm{w}$ poly (DL-lactide) (PLA) dissolved in $63.3 \% \mathrm{w} / \mathrm{w}$ $\mathrm{N}$-methyl-2-pyrrolidone (NMP). Syringe B contains doxycycline hyclate which is equivalent to $42.5 \mathrm{mg}$ doxycycline. Two separate syringes were coupled together just prior to use and mixed for 100 cycles. Once mixed, the $\mathrm{DH}$ gel was allowed to sit at room temperature for 15 minutes and then mixed for another 10 cycles before use. The constituted product is a pale yellow to yellow viscous liquid with a concentration of $8.5 \% \mathrm{w} / \mathrm{w}$ of doxycycline. ${ }^{1,5}$ Using a 23-gauge cannula attached to the delivery syringe the DH gel was slowly expressed into the periodontal pocket, starting from the base of the pocket, until it reached the gingival margin. As it begins to harden on contact with the moisture in the pocket and during the 1 to 2 minutes of hardening, it may be packed into pocket using the underside of a moistened curette in order to speed coagulation of polymer. ${ }^{15,16}$ The pockets were covered with CoePak which aids in retention of the system. Subjects returned at day 7 for removal of the dressing.

Chlosite $^{\circledast}$ (GHIMAS, Italy) is a xanthan based syringable gel system. The gel is a combination of two chlorhexidine formulations: $0.5 \%$ chlorhexidine digluconate and $1.0 \%$ chlorhexidine dihydrochloride incorporated in a saccharidic polymer, xanthan. 
Cross linking structure of xanthan controls the release of drugs and it exhibits a near zero order drug release. When in contact with water, it forms a three dimensional pseudoplastic reticulum capable of holding and maintaining various substances in suspension. ${ }^{10}$ The chlorhexidine xanthan based gel (CHX) undergoes a progressive process of imbibition and is physically removed in 10-30 days. Chlorhexidine digluconate is liberated in the first day and achieves a concentration $>100 \mu \mathrm{g} / \mathrm{ml}$ which is maintained for an average of 6-9 days which is greater than the minimum inhibitory concentration (MIC) for chlorhexidine $(0.10 \mu \mathrm{g} / \mathrm{ml})$. Chlorhexidine dihydrochloride is released in the following days and maintains the bacteriostatic and bactericidal concentrations for at least 2 weeks and prevents recolonization. The $\mathrm{CHX}$ gel is supplied with a special needle having a blunt tip and a lateral opening. This facilitates the application of the gel without traumatizing or damaging the periodontal tissues. After isolating and drying the sites, $\mathrm{CHX}$ gel was injected into the periodontal pocket and no periodontal dressing was used. ${ }^{10}$

\section{Treatment Procedures ${ }^{11}$}

All subjects received a full mouth supra- and subgingival SRP using an ultrasonic scaler and curettes. Subjects were given careful instructions in self performed oral hygiene measures; twice daily brushing using the modified Bass brushing technique with a soft toothbrush and a regular toothpaste with fluoride and once a day interdental cleaning using dental floss and/ or interdental brushes. The use of antimicrobial mouthrinses was not allowed during the study period. Subjects were instructed not to perform mechanical oral hygiene procedures (i.e., tooth brushing, flossing) on any treated areas for 7 days. The level of oral hygiene was checked at each recall visit and further instructions were given when indicated.

\section{Data Analysis}

The primary efficacy endpoints in the present trial were mean change in attachment level and mean change in pocket probing depth. A whole mouth measurement was taken. For all parameters, the subject mean was the basis of the statistical analysis, not the sites alone. The values were averaged across subjects.

Efficacy results for qualifying treated sites for CAL and PPD were analyzed statistically using Paired sample ' $t$ ' test. The null hypothesis was there were no significant changes in mean PPD or CAL in any treatment group. The alternative hypothesis was a difference existed in changes in mean PPD or CAL in between the three treatment groups. All statistical tests were 2-tailed and conducted at a significance level of $\leq 0.05$.

\section{Results}

\section{Plaque Indices and Gingival Indices}

The mean changes over time in plaque and gingival indices are given in Tables 1 and 2, respectively.

All subjects showed statistically and clinically significant improvements in whole mouth, gingival, and plaque indices at both follow up visits when compared to the baseline levels. The mean reduction in $\mathrm{PI}$ score from baseline to 1 month and 3 months was $0.99 \pm 0.36$ and $1.19 \pm 0.33$, respectively. The mean reduction in GI score from baseline to 1 month and 3 months was $0.89 \pm$ 0.47 and $1.09 \pm 0.44$, respectively.

Table 1. Comparison of subject mean values of PI scores at baseline, 1 month, and 3 months.

\begin{tabular}{|l|c|c|c|c|c|}
\hline Time interval & $\begin{array}{c}\text { Mean } \pm \text { SD } \\
\text { (in mm) }\end{array}$ & $\begin{array}{c}\text { Difference } \\
\text { from Baseline }\end{array}$ & P-value & $\begin{array}{c}\text { Difference from } \\
\text { 1 month }\end{array}$ & P-value \\
\hline Baseline & $1.68 \pm 0.33$ & & & & \\
\hline 1 Month & $0.69 \pm 0.09$ & $0.99 \pm 0.36$ & 0.001 & & \\
\hline 3 Months & $0.49 \pm 0.09$ & $1.19 \pm 0.33$ & 0.001 & $0.21 \pm 0.08$ & 0.001 \\
\hline
\end{tabular}


Table 2. Comparison of mean values of GI scores at baseline, 1 month, and 3 months.

\begin{tabular}{|l|c|c|c|c|c|}
\hline $\begin{array}{c}\text { Time } \\
\text { Interval }\end{array}$ & $\begin{array}{c}\text { Mean } \pm \text { SD } \\
\text { (in } \mathrm{mm} \text { ) }\end{array}$ & $\begin{array}{c}\text { Difference } \\
\text { from Baseline }\end{array}$ & P-value & $\begin{array}{c}\text { Difference from } \\
\text { 1 month }\end{array}$ & P-value \\
\hline Baseline & $1.54 \pm 0.45$ & & & & \\
\hline 1 Month & $0.64 \pm 0.12$ & $0.89 \pm 0.47$ & 0.001 & & \\
\hline 3 Months & $0.45 \pm 0.12$ & $1.09 \pm 0.44$ & 0.001 & $0.20 \pm 0.11$ & 0.001 \\
\hline
\end{tabular}

Table 3. Comparison of PPD at different observation periods in different groups.

\begin{tabular}{|c|c|c|c|c|c|c|}
\hline Group & $\begin{array}{c}\text { Observation } \\
\text { Period }\end{array}$ & $\begin{array}{c}\text { Mean } \pm \text { S.D } \\
\text { (in } \mathrm{mm} \text { ) }\end{array}$ & Comparison & Mean \pm S.D & 't'-Value & P-Value \\
\hline \multirow{4}{*}{$\mathrm{DH}+\mathrm{SRP}$} & Baseline (BL) & $6.16 \pm 1.17$ & & & & \\
\hline & 1 month $(1 \mathrm{M})$ & $4.16 \pm 0.98$ & BL vs $1 M$ & $2 \pm 0.83$ & $13.19^{\mathrm{S}}$ & 0.001 \\
\hline & 3 months $(3 \mathrm{M})$ & $3.43 \pm 0.72$ & $B L$ vs $3 M$ & $2.75 \pm 1.33$ & $11.19^{\mathrm{S}}$ & 0.001 \\
\hline & & & $1 \mathrm{M}$ vs $3 \mathrm{M}$ & $0.73 \pm 1.01$ & $4.17^{\mathrm{S}}$ & 0.001 \\
\hline \multirow{4}{*}{$\mathrm{CHX}+\mathrm{SRP}$} & Baseline (BL) & $6.40 \pm 0.89$ & & & & \\
\hline & 1 month $(1 \mathrm{M})$ & $4.63 \pm 1.21$ & BL vs $1 \mathrm{M}$ & $1.76 \pm 0.81$ & $11.84^{\mathrm{S}}$ & 0.001 \\
\hline & 3 months $(3 \mathrm{M})$ & $3.63 \pm 1.29$ & $B L$ vs $3 M$ & $2.76 \pm 1.25$ & $12.11^{\mathrm{S}}$ & 0.001 \\
\hline & & & $1 \mathrm{M}$ vs $3 \mathrm{M}$ & $1 \pm 0.90$ & $6.02^{S}$ & 0.001 \\
\hline \multirow{4}{*}{ SRP alone } & Baseline (BL) & $6.03 \pm 1.15$ & & & & \\
\hline & 1 month (1M) & $4.46 \pm 0.68$ & BL vs $1 \mathrm{M}$ & $1.56 \pm 1.50$ & $5.71^{\mathrm{S}}$ & 0.001 \\
\hline & 3 months (3M) & $4.30 \pm 0.87$ & $B L$ vs $3 M$ & $1.73 \pm 0.94$ & $10.05^{\mathrm{S}}$ & 0.001 \\
\hline & & & $1 M$ vs $3 M$ & $0.16 \pm 1.17$ & $0.77^{\mathrm{NS}}$ & 0.44 \\
\hline
\end{tabular}


Probing Pocket Depth

Table 3 shows changes in PPD for each treatment group.

At baseline, there were no statistically significant differences between the PPD of the treated sites. All sites showed significant changes in PPD from baseline after 1 and 3 months. Mean PPD reduction from baseline to 1 and 3 months was $2.00 \pm 0.83$ and $2.73 \pm 1.33$ for $\mathrm{DH}+\mathrm{SRP}$, respectively; $1.76 \pm 0.81$ and $2.76 \pm 1.25$, for
$\mathrm{CHX}+\mathrm{SRP}$, respectively; and $1.56 \pm 1.50$ and 1.73 \pm 0.94 for SRP alone, respectively. The reduction in mean PPD from 1 to 3 months was found to be significant for $\mathrm{DH}+\mathrm{SRP}(0.73 \pm 1.01)$ and CHX+SRP $(1.0 \pm 0.90)(p<0.001)$ but not for SRP alone $(0.16 \pm 1.17)(p=0.44)$ (Figures 1 and 2$)$.

Between treatment comparisons, at 1 month, found no significant differences in mean PPD reduction between $\mathrm{DH}+\mathrm{SRP}, \mathrm{CHX}+\mathrm{SRP}$, or SRP alone. At 3 months, both $\mathrm{DH}+\mathrm{SRP}(0.86$

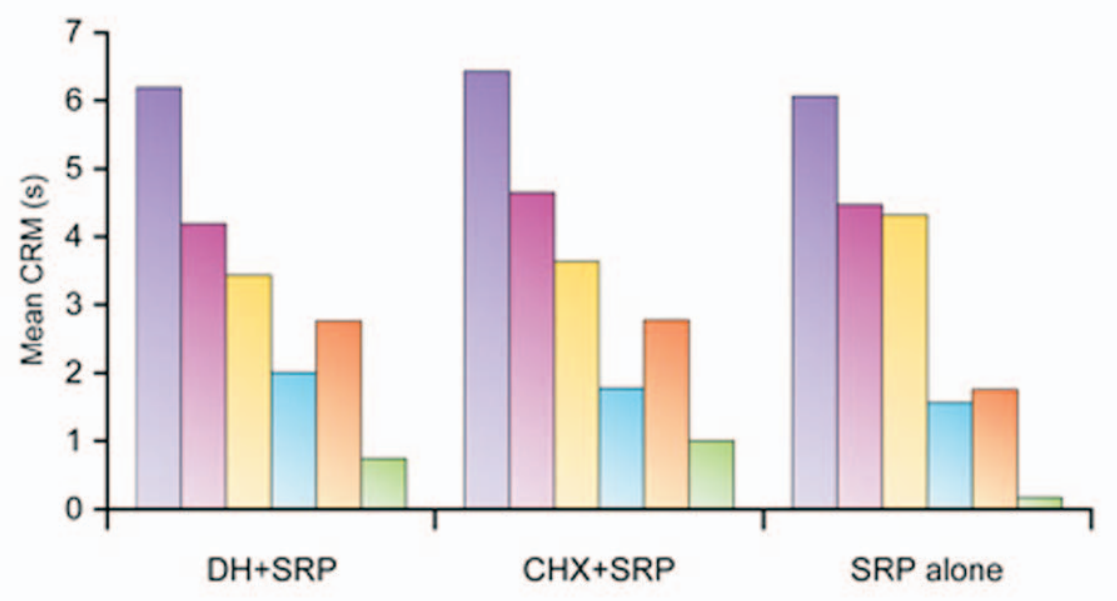

$\square$ Baseline $\square$ Month $\square$ 3Months $\square$ BL-1M $\square$ BL-3M $\square 1 \mathrm{M}-3 \mathrm{M}$

Figure 1. Mean values of PPDs in the groups at different time intervals.

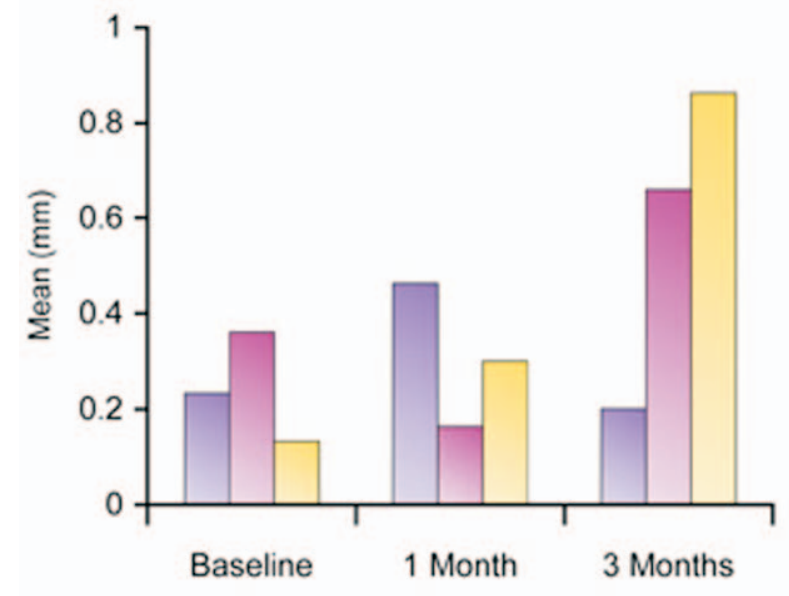

$\square$ DHvsChX $\square$ CHXvsSRP $\square$ DHvsSRP

Figure 2. Intergroup comparison of mean values of PPD at different observation periods. 
Table 4. Intergroup comparison of PPD at different observation periods.

\begin{tabular}{|c|c|c|c|c|c|c|}
\hline & Group & Mean \pm S.D & Comparison & Mean \pm S.D & 't'-value & $P$ value \\
\hline \multirow{3}{*}{ Baseline } & $\mathrm{DH}+\mathrm{SRP}$ & $6.16 \pm 1.17$ & $\mathrm{DH}+\mathrm{SRP}$ vs $\mathrm{CHX}+\mathrm{SRP}$ & $0.23 \pm 1.27$ & $1.00^{\mathrm{NS}}$ & 0.32 \\
\hline & CHX+SRP & $6.40 \pm 0.89$ & $\mathrm{CHX}+\mathrm{SRP}$ vs SRP alone & $0.36 \pm 1.35$ & $1.48^{\mathrm{NS}}$ & 0.14 \\
\hline & SRP alone & $6.03 \pm 1.15$ & DH+SRP vs SRP alone & $0.13 \pm 1.75$ & $0.41^{\mathrm{NS}}$ & 0.68 \\
\hline \multirow{3}{*}{1 Month } & $\mathrm{DH}+\mathrm{SRP}$ & $4.16 \pm 0.98$ & $\mathrm{DH}+\mathrm{SRP}$ vs $\mathrm{CHX}+\mathrm{SRP}$ & $0.46 \pm 1.43$ & $1.78^{\mathrm{NS}}$ & 0.08 \\
\hline & CHX+SRP & $4.63 \pm 1.21$ & $\mathrm{CHX}+\mathrm{SRP}$ vs SRP alone & $0.16 \pm 1.36$ & $0.66^{\text {NS }}$ & 0.50 \\
\hline & SRP alone & $4.46 \pm 0.68$ & DH+SRP vs SRP alone & $0.30 \pm 0.98$ & $1.66^{\mathrm{NS}}$ & 0.10 \\
\hline \multirow{3}{*}{3 Months } & $\mathrm{DH}+\mathrm{SRP}$ & $3.43 \pm 0.72$ & $\mathrm{DH}+\mathrm{SRP}$ vs $\mathrm{CHX}+\mathrm{SRP}$ & $0.20 \pm 1.47$ & $0.74^{\mathrm{NS}}$ & 0.46 \\
\hline & CHX+SRP & $3.63 \pm 1.04$ & $\mathrm{CHX}+\mathrm{SRP}$ vs SRP alone & $0.66 \pm 1.58$ & $2.3^{\mathrm{NS}}$ & 0.02 \\
\hline & SRP alone & $4.30 \pm 0.87$ & DH+SRP vs SRP alone & $0.86 \pm 1.0$ & $4.7^{\mathrm{s}}$ & 0.001 \\
\hline \multicolumn{7}{|c|}{$\begin{array}{l}\text { S = sign ficant } \\
\text { NS = non-significant }\end{array}$} \\
\hline
\end{tabular}

$\pm 1.0)$ and $\mathrm{CHX}+\mathrm{SRP}(0.66 \pm 1.58)$ showed an additional PPD reduction compared to SRP alone which was statistically significant $(p<0.02)$. Differences in mean pocket depth reduction between $\mathrm{DH}+\mathrm{SRP}$ and $\mathrm{CHX}+\mathrm{SRP}$ were not significant $(p=0.46)$ (Table 4).

\section{Clinical Attachment Level}

Statistically significant relative CAL gains were reported for all treatment groups at 1 and 3 months. Mean CAL from baseline to 1 and 3 months was $1.03 \pm 0.49$ and $1.73 \pm 0.90$ for $\mathrm{DH}+\mathrm{SRP}$, respectively; $1.33 \pm 0.66$ and $2.03 \pm$ 1.12 for $\mathrm{CHX}+\mathrm{SRP}$, respectively; and $0.73 \pm 0.58$ and $0.86 \pm 0.68$ for SRP alone, respectively. Changes in CAL are shown in Table 5.

As shown in Table 6, treatment comparisons at 1 month showed no significant differences in CAL between any of the treatment groups, $\mathrm{DH}+\mathrm{SRP}, \mathrm{CHX}+\mathrm{SRP}$, or SRP alone. At 3 months, differences in relative $\mathrm{CAL}$ for both $\mathrm{DH}+\mathrm{SRP}$ $(0.80 \pm 0.92, p=0.001)$ and $\mathrm{CHX}+\mathrm{SRP}(0.63$ $\pm 1.47, p=0.02$ ) were statistically significant compared to SRP alone. Difference in relative CAL between $\mathrm{DH}+\mathrm{SRP}$ and $\mathrm{CHX}+\mathrm{SRP}$ was non significant $(0.16 \pm 1.48)$ (Figures 3 and 4$)$.

\section{Discussion}

\section{Study Design}

The present study was designed to evaluate and compare the clinical efficacy of a locally delivered $10 \%$ doxycycline hyclate gel and a xanthan based chlorhexidine gel when used as an adjunct to SRP. It is well established the organized structure of biofilm can block proper diffusion or even inactivate pharmacological agents subgingivally. Thus, previous biofilm removal could favor greater effectiveness of the antibiotic against subgingival pathogens, favoring the adjunctive therapy done in the present study. ${ }^{17}$

Split mouth clinical trials have been used previously for the evaluation of locally applied subgingival antimicrobials in periodontal therapy. ${ }^{18,19}$ However, when comparing different treatment modes within the same dentition, carryacross or spill-over effects may occur. ${ }^{20}$ In the present study selected interproximal sites were at least one tooth apart, possibly minimizing the interaction between treatment gels. ${ }^{18,19}$

\section{Study Population}

Subjects with an age range of 25-75 years were 
Table 5. Comparison of CAL at different observation periods in different groups.

\begin{tabular}{|c|c|c|c|c|c|c|}
\hline Group & $\begin{array}{c}\text { Observation } \\
\text { period }\end{array}$ & $\begin{array}{c}\text { Mean } \pm S . D \\
\text { (in } \mathrm{mm} \text { ) }\end{array}$ & Comparison & Mean \pm S.D & 't'-value & P value \\
\hline \multirow{4}{*}{$\mathrm{DH}+\mathrm{SRP}$} & Baseline (BL) & $6.06 \pm 1.14$ & & & & \\
\hline & 1 month (1M) & $5.03 \pm 0.99$ & $B L$ vs $1 M$ & $1.03 \pm 0.49$ & $11.54^{\mathrm{S}}$ & 0.001 \\
\hline & 3 months $(3 \mathrm{M})$ & $4.33 \pm 0.66$ & BL vs $3 M$ & $1.73 \pm 0.90$ & $10.46^{\mathrm{S}}$ & 0.001 \\
\hline & & & $1 \mathrm{M}$ vs $3 \mathrm{M}$ & $0.70 \pm 0.70$ & $5.46^{\mathrm{S}}$ & 0.001 \\
\hline \multirow{4}{*}{$\mathrm{CHX}+\mathrm{SRP}$} & Baseline (BL) & $6.53 \pm 1.00$ & & & & \\
\hline & 1 month (1M) & $5.20 \pm 1.15$ & $B L$ vs $1 M$ & $1.33 \pm 0.66$ & $11.05^{\mathrm{S}}$ & 0.001 \\
\hline & 3 months( $3 M)$ & $4.50 \pm 1.30$ & BL vs $3 M$ & $2.03 \pm 1.12$ & $9.86^{\mathrm{s}}$ & 0.001 \\
\hline & & & $1 \mathrm{M}$ vs $3 \mathrm{M}$ & $0.70 \pm 0.70$ & $5.46^{\mathrm{s}}$ & 0.001 \\
\hline \multirow{4}{*}{$\begin{array}{l}\text { SRP } \\
\text { alone }\end{array}$} & Baseline (BL) & $6.00 \pm 1.11$ & & & & \\
\hline & 1 month (1M) & $5.26 \pm 0.86$ & $B L$ vs $1 M$ & $0.73 \pm 0.58$ & $6.88^{S}$ & 0.001 \\
\hline & 3 months $(3 \mathrm{M})$ & $5.13 \pm 0.86$ & $B L$ vs $3 M$ & $0.86 \pm 0.68$ & $6.96^{\mathrm{S}}$ & 0.001 \\
\hline & & & $1 \mathrm{M}$ vs $3 \mathrm{M}$ & $0.13 \pm 0.43$ & $1.68^{\mathrm{NS}}$ & 0.10 \\
\hline
\end{tabular}

Table 6. Intergroup comparison of CAL at different observation periods.

\begin{tabular}{|c|c|c|c|c|c|c|}
\hline & Group & Mean \pm S.D & Comparison & Meant S.D & 't'-value & P value \\
\hline \multirow{3}{*}{ Baseline } & $\mathrm{DH}+\mathrm{SRP}$ & $6.06 \pm 1.14$ & $\mathrm{DH}+\mathrm{SRP}$ vs $\mathrm{CHX}+\mathrm{SRP}$ & $0.46 \pm 1.30$ & $1.9^{\mathrm{NS}}$ & 0.006 \\
\hline & CHX+SRP & $6.53 \pm 1.00$ & CHX+SRP vs SRP alone & $0.53 \pm 1.27$ & $2.28^{S}$ & 0.03 \\
\hline & SRP alone & $6.00 \pm 1.11$ & DH+SRP vs SRP alone & $0.02 \pm 0.69$ & $0.52^{\mathrm{NS}}$ & 0.60 \\
\hline \multirow{3}{*}{1 Month } & $\mathrm{DH}+\mathrm{SRP}$ & $5.03 \pm 0.99$ & DH+SRP vs CHX+SRP & $0.16 \pm 1.53$ & $0.59^{\mathrm{NS}}$ & 0.55 \\
\hline & CHX+SRP & $5.20 \pm 1.15$ & CHX+SRP vs SRP alone & $0.02 \pm 1.28$ & $0.28^{\mathrm{NS}}$ & 0.77 \\
\hline & SRP alone & $5.26 \pm 0.89$ & DH+SRP vs SRP alone & $0.23 \pm 0.77$ & $1.65^{\mathrm{NS}}$ & 0.10 \\
\hline \multirow{3}{*}{3 Months } & $\mathrm{DH}+\mathrm{SRP}$ & $4.33 \pm 0.66$ & DH+SRP vs $\mathrm{CHX}+\mathrm{SRP}$ & $0.16 \pm 1.48$ & $0.61^{\mathrm{NS}}$ & 0.54 \\
\hline & CHX+SRP & $4.50 \pm 1.30$ & $\mathrm{CHX}+$ SRP vs SRP alone & $0.63 \pm 1.47$ & $2.35^{\mathrm{S}}$ & 0.02 \\
\hline & SRP alone & $5.13 \pm 0.86$ & DH+SRP vs SRP alone & $0.80 \pm 0.92$ & $4.73^{\mathrm{s}}$ & 0.001 \\
\hline
\end{tabular}




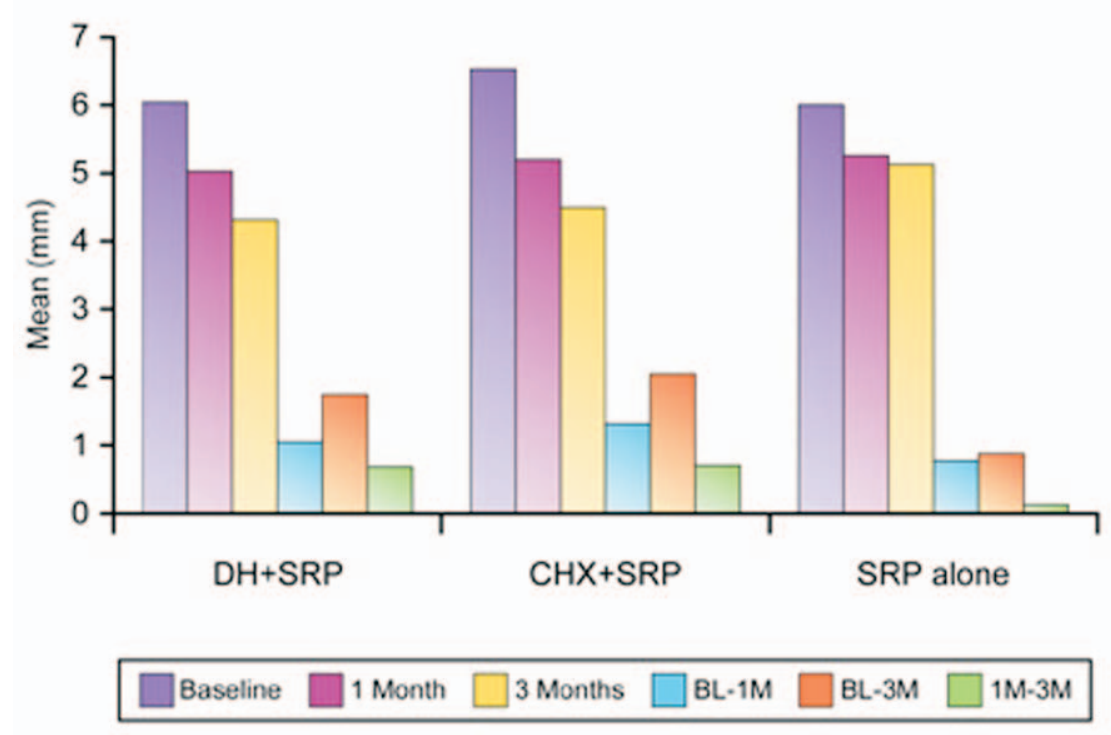

Figure 3. Mean values of CAL at different time intervals.

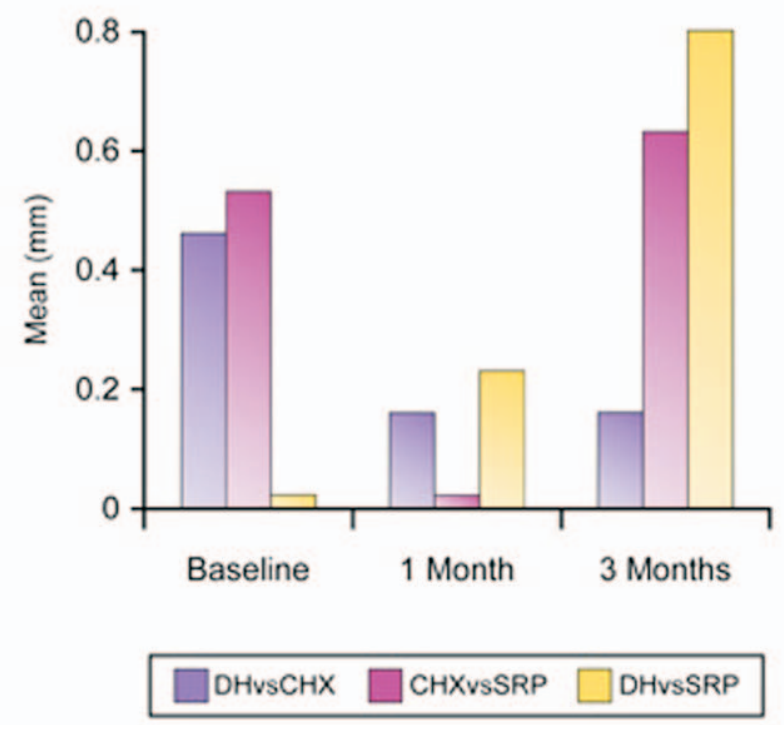

Figure 4. Intergroup comparison of mean values of $\mathrm{CAL}$ at different observation periods.

recruited in the study. Subjects in this age range generally present with chronic periodontitis and can maintain proper study protocol. Subjects with a history of local and/or systemic antibiotic therapy within the last 6 months before baseline examination were excluded due to the likelihood of bacterial resistance expected in the microflora of such individuals. ${ }^{21}$ Subjects who have had an oral prophylaxis 2 months prior to the baseline examination were also avoided. Listgarten et al.
$(1978)^{22}$ showed the proportion of coccoid cells (dominant at clinically healthy sites) increased as a result of SRP. Pregnant women were excluded as tetracyclines may cross the placenta and can have toxic effects on the developing fetus. Lactating mothers were excluded as well because of the potential for serious adverse reactions in nursing infants from doxycycline as tetracyclines can appear in breast milk following oral administration. 


\section{Reproducibility}

All measurements were performed using a manual probe, UNC \#15 periodontal probe with a visual read out that was not force controlled. $\mathrm{Knoll} \mathrm{Kohler}^{23}$ suggested force controlled automated probes for controlled clinical trials to ensure proper measurement accuracy. However, others failed to observe a significantly improved reproducibility of PPD measurements after use of a force controlled probe with visual read out to the nearest $0.5 \mathrm{~mm}$ compared to a simple manual probe. ${ }^{24}$ Mayfield et al. ${ }^{25}$ observed better intra- and inter- individual reproducibility using a manual probe in comparison to simple (TPS) and automated force-controlled probes (Florida probe, Periprobe). All measurements were highly standardized using a reference stent. Reliability and reproducibility of measurements is better using occlusal stent reference. ${ }^{26}$

\section{Treatment Effect}

Both the gingival and plaque indices remained satisfactory during the entire study period, suggesting patients complied with the oral hygiene instructions. The reduction in plaque and gingival scores could be due to the proper oral hygiene maintenance and the thoroughness of SRP.

Clinical improvements, reduction in PPD, and gain in CAL, seen following extensive SRP (alone), are apparently due to reduction of inflammation secondary to alteration in the subgingival bacteria. ${ }^{27,28}$ In addition to the elimination of local etiological factors, it has been recently proposed a scaling procedure may also elicit a local and systemic host response that would aid in eliminating local infection and promote healing. In addition, the intentional and/or inadvertent removal of inflamed tissue and pocket epithelium associated with SRP would be followed by a healing phase in which new epithelial attachment and connective attachment would form a regenerated periodontal support. ${ }^{29}$

In the doxycycline treated group, DH+SRP, the clinical reduction in PPD was substantial and consistent with a reduction of inflammation in the adjacent gingival tissues. This reduction in inflammation and presence of healing in the connective tissue subjacent to the junctional epithelium has been shown to be the primary reason for reducing the depth of periodontal probe penetration after standard treatment. ${ }^{30}$ The enhanced response may be, in part, related to the additional property of doxycycline to inhibit tissue collagenase activity. The seemingly greater closure of pockets could have been enhanced by the possibility of doxycycline adsorbing onto the mineralized dental structures where it may act as a transient reservoir of the antimicrobial agent during a period of substantivity. ${ }^{31}$

In the chlorhexidine treated group, $\mathrm{CHX}+\mathrm{SRP}$, PPD reduction can be attributed to the bactericidal concentrations achieved within day 1 at the selected sites, and these higher concentration levels were maintained for 2 weeks thereafter. Therefore, enhanced healing may have occurred at the test sites in the absence or following reduction of microbial load. ${ }^{10}$

The greater gain in CAL in DH+SRP and $\mathrm{CHX}+\mathrm{SRP}$ could be attributed to the absence of bacterial challenge during the critical initial phase of healing following SRP.

The results observed in this study are in agreement with observations reported by Wennstrom et al. ${ }^{11}$ and Eickholz et al. ${ }^{11}$ At 3 months, the percentage of sites showing pocket depth reduction of $\geq 2 \mathrm{~mm}$ was the similar in $\mathrm{DH}+\mathrm{SRP}$ and $\mathrm{CHX}+\mathrm{SRP}$ (Table 7).

Table 7. Percentage of sites showing PPD change in different groups from baseline to 3 months.

\begin{tabular}{|l|c|c|c|}
\hline \multicolumn{1}{|c|}{$\mathbf{n}=\mathbf{3 0}$ sites } & DH+SRP & CHX+SRP & SPR alone \\
\hline Decrease of $1 \mathrm{~mm}$ & $10 \%$ & $13.33 \%$ & $20 \%$ \\
\hline Decrease $\geq 2 \mathrm{~mm}$ & $83.33 \%$ & $83.33 \%$ & $66.66 \%$ \\
\hline No change & $6.66 \%$ & $3.33 \%$ & $13.33 \%$ \\
\hline
\end{tabular}


Table 8. Percentage of sites showing relative CAL in different groups from baseline to 3 months.

\begin{tabular}{|l|c|c|c|}
\hline \multicolumn{1}{|c|}{$\mathbf{n}=30$ sites } & DH+SRP & CHX+SRP & SPR alone \\
\hline Relative gain of $1 \mathrm{~mm}$ & $43.33 \%$ & $26.66 \%$ & $53.33 \%$ \\
\hline Relative gain $\geq 2 \mathrm{~mm}$ & $53.33 \%$ & $66.66 \%$ & $16.66 \%$ \\
\hline No change & $3.33 \%$ & $6.66 \%$ & $30 \%$ \\
\hline
\end{tabular}

The percentage of sites showing relative CAL gain was greater in $\mathrm{CHX}+\mathrm{SRP}$ sites $(66.66 \%)$ as compared to $\mathrm{DH}+\mathrm{SRP}$ sites (53.33\%), however, this difference was not significant. This slight advantage for $\mathrm{CHX}+\mathrm{SRP}$ could be attributed to the formulation (Chlosite ${ }^{\oplus}$ ) used which is a combination of fast releasing chlorhexidine digluconate and slow releasing chlorhexidine dihydrochloride. This combination might have provided enhanced bactericidal effects during the healing phase (Table 8).

\section{Conclusion}

Local drug therapy markedly improves the benefits of SRP, and by the use of these agents the threshold for surgical periodontal therapy might be moved towards deeper pockets. Further studies are needed to evaluate the long-term clinical advantages of this adjunctive therapy to determine which types of patients and lesions will benefit most from the incorporation of locally delivered agents. Furthermore, microbiological studies are also required to corroborate with the clinical findings observed.

\section{Clinical Significance}

The scientific and clinical rationale for local drug delivery includes the following:

- To destroy or inhibit any remaining periodontopathogens following mechanical debridement

- To destroy or inhibit bacteria that have invaded the tissues

- To prevent recolonization of bacteria during healing phase following therapy

The use of local drug therapy may refocus the need for surgical periodontal therapy toward deeper pockets. 


\section{References}

1. Hancok EB, Newell DH. Antimicrobials in periodontal practice. Dent Clin North America; 1996; 38:719-731.

2. Goodson JM. Pharmacokinetic principles controlling efficacy of oral therapy. J Dent Res 1989; 68(spec issue): $1625-1632$.

3. Oosterwall PJ, Mikx FH, Renggli $\mathrm{HH}$. Clearance of a topically applied flouroscien gel from periodontal pocket. J Clin Periodontol 1990; 17:613-615.

4. Kim TS, Klimpel H, Fiehn W. Comparison of the pharmacokinetic profiles of two locally administered doxycycline gels in crevicular fluid and saliva. J Clin Periodontol 2004; 31:286-292.

5. Greenstein G, Polson AM. The role of local drug delivery in the management of periodontal diseases: A comprehensive review. J Periodontol 1998; 69:507-520.

6. Martorelli de Lima AF, Cury CC. Therapy with adjunctive doxycycline local delivery in patients with type 1 diabetes mellitus and periodontitis. J Clin Periodontol 2004; 31:648-653.

7. Lauhio A, Sorsa T, Lindy O, Sumalainen K, Saari H, Golub LM, Konttinen YT. Anticollagenolytic potential of tetracycline in long term treatment of reactive arthritis. Arthritis Rheumatoid 1992; 35:195-198.

8. Sorsa T, Uitto VJ, Suomalainen K, Vauhkonen M, Lindy S. Comparison of interstitial collagenase from human gingival, sulcular fluid and polymorphonuclear leukocyte. J Periodontal Res 1998; 23:386-393.

9. Demirel K, Baer PN, McNamara TF. Topical application of doxycycline on periodontally involved root surfaces in vitro: Comparative analysis of substantivity on cementum and dentin. J Periodontol 1991; 62:312-316.

10. Rusu D, Benta A, Necker A. Non-surgical periodontal therapy using a novel chlorhexidine based xanthan gel; a split mout study. Int Poster J Dent Oral Med 2005; 7:286-291.

11. Wennstrom JL, Newman HN, MacNeill SR. Utilization of locally delivered doxycycline in non-surgical treatment of chronic periodontitis. A comparative multi-center trial of 2 treatment approaches. J Clin Periodontol 2001; 28:753-761.

12. Silness J, Loe H. Periodontal disease in pregnancy. II. Correlation between oral hygiene and periodontal condition. Acta Odontol Scand 1964; 22:121-135.

13. Loe H, Silness J. Periodontal disease in pregnancy. I. Prevalence and severity. Acta Odontol Scand 1963; 21:533-551.

14. Eickholz P, Kim TS, Burklin T. Non-surgical periodontal therapy with adjunctive topical doxycycline: a double blind randomized controlled multicenter study. (1). Study design and clinical results. J Clin Periodontol 2002; 29:108-117.

15. Garrett S, Johnson L, Drisko CH. Two multi-center studies evaluating locally delivered doxycycline hyclate, placebo control, oral hygiene, and scaling and root planing in the treatment of periodontitis. J Periodontol 1999; 70:490-503.

16. Killoy WJ, Polson AM. Controlled local delivery of antimicrobials in the treatment of periodontitis. Dent Clin North America 1998; 42:263-283.

17. Anwar H, Strap JI, .Costerton JW. Establishment of aging biofilms: possible mechanism of bacterial resistance to antibiotic therapy. Antimicrobial agents and chemotherapy 1992; 36:1347-1351.

18. Goodson JM, Cugini MA, Kent RL, Armitage GC, Cobb CM, Fine D, Fritz ME, Green E, Imoberdorf MJ, Killoy WJ, Mendieta C, Niederman R, Offenbacher S, Taggart E, Tonetti M. Multicentre evaluation of tetracycline fibre therapy: i experimental design, methods and baseline data. J Periodontal Res 1991; Jul;26(4)361-70.

19. Goodson JM, Cugini MA, Kent RL, Armitage GC, Cobb CM, Fine D, Fritz ME, Green E, Imoberdorf MJ, Killoy WJ, Mendieta C, Niederman R, Offenbacher S, Taggart E, Tonetti M. Multicentre evaluation of tetracycline fibre therapy: ii experimental design, methods and baseline data. J Periodontol Res 1991; 26(4):371-79.

20. Hujoel PP, DeRouen TA. Validity issues in split mouth trials. J Clin Periodontol 1992; Oct;19 (9 Pt 1):625-7. 
21. Magnusson I, Marks RG, Clark, WB, Walker GB, Low SB, Mac Arthur WP. Clinical microbiological and immunological characteristics of subjects with refractory periodontitis. J Clin Periodontol 1991; 18:291-299.

22. Listgarten MA, Lindhe J, Hellden L. Effect of tetracycline and or scaling on human disease. J Clin Periodontol 1978; 5:246-271.

23. Knoll-Kohler E. Metronidazole dental gel as an alternative to scaling and root planning in the treatment of localized juvenile periodontitis and its efficacy period. Eur J Oral Sci.1999; 107: 415-421.

24. Grossi SG, Skrepcinski FB, DeCaro T, Robertson DC, Ho AW, Dunford RG, Genco RJ. Treatment of periodontal in diabetic reduced glycated reduced hemoglobin. J Periodontol 1997; 68(8):713-719.

25. Mayfield L, Bratthall G, Attström R. Periodontal probe precision using 4 different periodontal probes. J Clin Periodontol. 1996 Feb;23(2):76-82.

26. Gibbs $\mathrm{CH}$, Hirschfeld JW, Lee JG. Description and clinical evaluation of a new computerized periodontal probe. J Clin Periodontol 1998; 15:137-144.

27. Llambes F, Silvestre FJ. Effect of non-surgical periodontal treatment with or without doxycycline on the periodontium of type 1 diabetic patients. J Clin Periodontol 2005; 32:915-920.

28. Fowler EB, Breaut LG, Dryant JB. Site specific chlohexidine - a periodontal alternative. Gen Dent 2001; 49(1):84-88.

29. Offenbacher S. Periodontal diseases pathogenesis. Ann Periodontol. 1996 Nov;1(1):821-78.

30. Ryder MI, Pons B, Adams D. Effects of smoking on local delivery of controlled release doxycycline as compared to scaling and root planing. J Clin Periodontol 1999; 26:683-691.

31. Polson AM, Garrett S, Stoller NH. Multi-center comparative evaluation of subgingivally delivered sanguinarine and doxycycline in the treatment of periodontitis. II. Clinical results. J Periodontol 1997; 68:119-126.

\section{About the Authors}
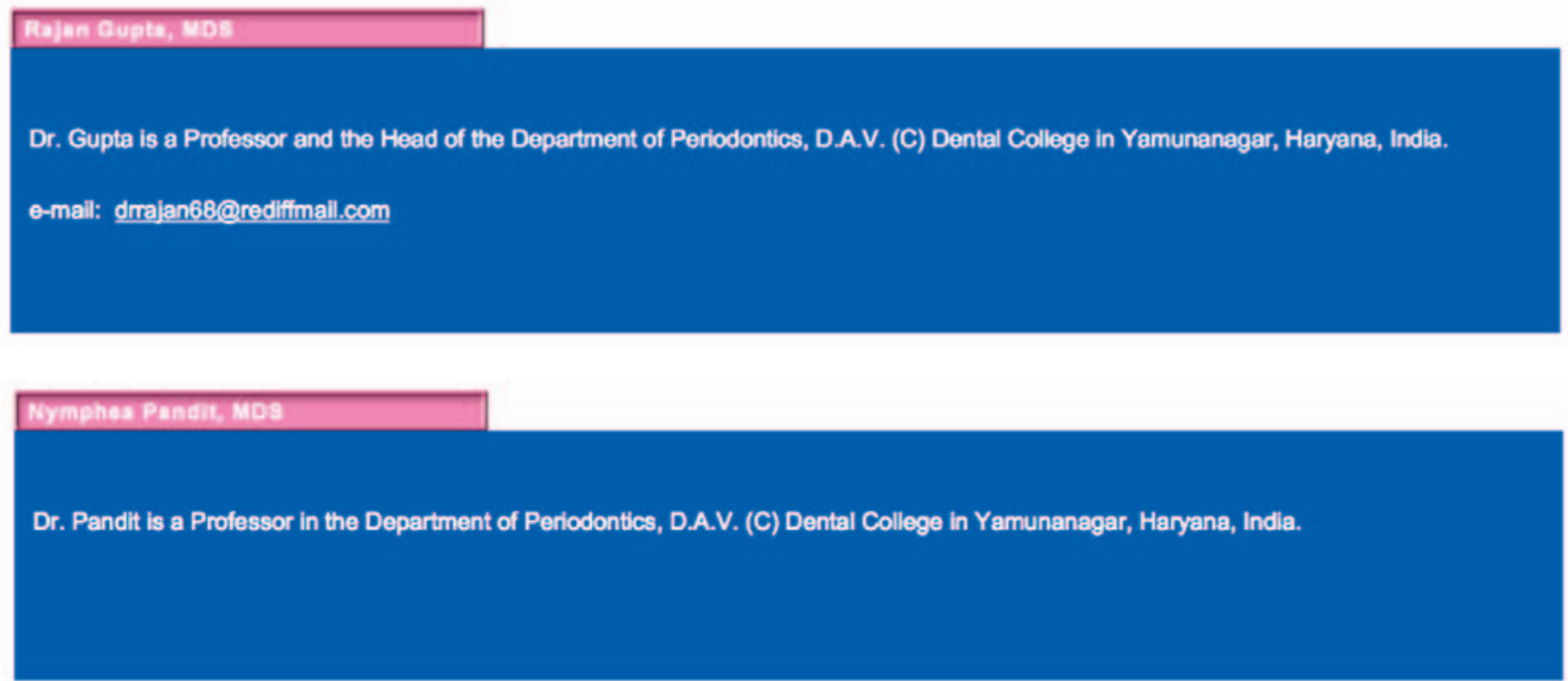
Dr. Aggarwal is a postgraduate student in the Department of Periodontics, D.A.V. (C) Dental College in Yamunanagar, Haryana, India.

\section{Ashish Vorma, Mos}

Dr. Verma is a former postgraduate student in the Department of Periodontics, D.A.V. (C) Dental College in Yamunanagar, Haryana, Indla. 